\title{
Trophic niche differences between two congeneric goby species: evidence for ontogenetic diet shift and habitat use
}

\author{
Zhiqiang Guo ${ }^{1,2,3}$, Jiashou Liu ${ }^{1, *}$, Sovan Lek ${ }^{1,2}$, Zhongjie Li ${ }^{1}$, Fengyue Zhu ${ }^{1}$, \\ Jianfeng Tang ${ }^{1}$, Julien Cucherousset ${ }^{2}$ \\ ${ }^{1}$ State Key Laboratory of Freshwater Ecology and Biotechnology, Institute of Hydrobiology, \\ Chinese Academy of Sciences, Wuhan 430072, PR China \\ ${ }^{2}$ CNRS, Université Paul Sabatier, ENFA, UMR5174 EDB (Laboratoire Évolution \& Diversité Biologique), \\ 118 route de Narbonne, 31062 Toulouse, France \\ ${ }^{3}$ State Key Laboratory of Oceanography in the Tropics, South China Sea Institute of Oceanology, \\ Chinese Academy of Sciences, Guangzhou 510301, PR China
}

\begin{abstract}
Food partitioning is one of the primary mechanisms facilitating the stable cooccurrence of competing species, but very few studies have investigated how food resource use of competing and closely related species varies with life-history stages and habitats. In Lake Erhai (China), the trophic niche of 2 congeneric and co-occurring invasive goby species (Rhinogobius cliffordpopei and $R$. giurinus) was examined to test the existence of an ontogenetic diet shift and to determine potential differences in trophic niche between species within a habitat and between habitats (i.e. littoral and profundal) within species. Results obtained from gut content and stable isotope analyses revealed a strong trophic niche shift during ontogeny, whereby juveniles mainly consumed macrozooplankton while sub-adults and adults increasingly consumed aquatic insects and Tubificidae. The trophic niche of juveniles was similar between species in each of the 2 habitats but significantly different for sub-adults and adults, notably in littoral habitat. Moreover, the trophic niche was similar between habitats for juveniles of each species, whereas it differed significantly between habitats for sub-adults and adults. This study demonstrates the importance of ontogeny and shows that habitat use can significantly affect food resource use and trophic relationships between 2 co-occurring fish species.
\end{abstract}

KEY WORDS: Species co-occurrence - Niche differentiation - Ontogenetic niche shift - Stable isotope analyses $\cdot$ Rhinogobius $\cdot$ Gut content analysis

\section{INTRODUCTION}

Niche theory predicts that species-specific specialization in resource use is a primary mechanism allowing the stable coexistence among competing species within a local community (Chesson 2000, Kylafis \& Loreau 2011). Specialization in food resources is crucial since it may substantially enhance coexistence by reducing interspecific competition (Gabler \& Amundsen 2010, Kleynhans et al. 2011). In fish, for instance, some closely related species co-existing in the same ecosystem display strong food resource differentiation and trophic niche specialization (Colloca et al. 2010, Davis et al. 2012). Since the diet and foraging behavior of fishes are often strongly driven by environmental conditions such as prey availability (Shimose et al. 2010), competition (Kaspersson et al. 2010), and predation (Hammerschlag et al. 2010), the patterns of food use among potentially competing fishes might therefore also vary between habitats 
with different environmental characteristics (Davis et al. 2012). However, few studies have focused on the potential effects of habitat characteristics on trophic resource use among competing and closely related fish species.

Most animals show complex life cycles with significant shifts in their ecological niches during ontogeny, and conspecific individuals can display varying trophic resource exploitation due to morphological, physiological, and/or behavioral differences between life-history stages (Specziár \& Rezsu 2009). The magnitude of resource partitioning among competing species may therefore differ during ontogeny. Consequently, investigations based on a single life-history stage could potentially provide inaccurate information to elucidate the trophic relationships between co-occurring species (Specziár \& Rezsu 2009). Fishes have complex age/size-structured populations, and the range of body sizes between conspecific individuals can sometimes span several orders of magnitude (Specziár \& Rezsu 2009, Davis et al. 2012). During ontogeny, strong niche shifts can occur, with individuals belonging to different trophic guilds during their life cycle. As a result, the patterns of food resource use among co-occurring fish species are often made more complex by ontogeny-dependent interactions (Nakayama \& Fuiman 2010, Davis et al. 2012). Consequently, investigating food resource use between competing fish species at different life-history stages is crucial for a better understanding of their trophic relationship.

Rhinogobius cliffordpopei (Rutter 1897) and R. giurinus (Nichols 1925) are highly invasive fish species in Yunnan-Guizhou Plateau of China (Xie et al. 2001, Yuan et al. 2010). They were inadvertently introduced into most lakes of the Yunnan-Guizhou Plateau in the 1950s and 1960s and introduced simultaneously to Lake Erhai in 1961 (Du \& Li 2001, Xie et al. 2001, Yuan et al. 2010). They represent a rare case where 2 introduced species became simultaneously abundant and are considered to be one of the major causes of the decline and/or extirpation of native fishes in Lake Erhai (Du \& Li 2001). R. cliffordpopei spawns from February to June, with a spawning peak occurring in March and April. Spawning activity of $R$. giurinus occurs from April to August with a peak activity during May and June (Guo et al. 2013). In lakes along the middle and lower reaches of the Yangtze River in China, where the 2 gobies are native, species diets (sub-adults and adults) are mainly large zooplankton (Cladocera and Copepoda) and aquatic insects (chironomid larvae) (Xie et al. 2000, 2005, Zhang 2005). However, no study has focused on ontogenetic trophic niche shifts and trophic relationships between the 2 species. Moreover, a strong spatial segregation between the 2 species occurs in Lake Erhai (Guo et al. 2012), and we aimed to test whether this is associated with food resource partitioning within and between habitats, a process that may facilitate the co-occurrence of the 2 species at high abundance. Specifically, the trophic niches of the 2 species were quantified using gut content analysis (GCA) and stable isotope analysis (SIA), and we aimed to determine (1) how the trophic niche shifts during ontogeny for each species; (2) whether the trophic niche in each habitat differs between species; and (3) whether the trophic niche of each species differs between habitats.

\section{MATERIALS AND METHODS}

\section{Study area}

Lake Erhai is located in the Yunnan-Guizhou Plateau, southwestern China. It is a freshwater lake with a water surface area of $250 \mathrm{~km}^{2}$ and maximum water depth of $21 \mathrm{~m}$ in 2010 (see details in Guo et al. 2012). The fish assemblage of the lake is currently composed of 28 fish species (7 native and 21 nonnative species). Rhinogobius cliffordpopei and $R$. giurinus are the most abundant benthic fish species. The littoral habitat (water depth $<6 \mathrm{~m}$ ) of the lake was characterized by relatively high abundances of submerged macrophytes, R. cliffordpopei, and certain other fish species but low abundance of $R$. giurinus (including juveniles and adults, Guo et al. 2012). Conversely, the profundal habitat (water depth ranging from 12 to $20 \mathrm{~m}$ ) was characterized by the absence of submerged macrophytes, high abundance of $R$. giurinus, but low abundance of $R$. cliffordpopei and other fish species (Guo et al. 2012). The main food resources available for the 2 gobies differed between the 2 habitats, i.e. the abundances of macrozooplankton and aquatic insects were higher in the littoral habitat compared to the profundal habitat, while the abundance of Tubificidae and shrimp larvae were higher in profundal habitat compared to littoral habitat (Guo et al. 2012).

\section{Fish sampling}

Rhinogobius cliffordpopei and $R$. giurinus were collected using benthic fyke nets from May to August 2010 (total $4 \mathrm{mo}$ ). The nets comprised 20 traps (each 
$0.60 \times 0.62 \times 0.35 \mathrm{~m}), 2$ end-traps $(1 \mathrm{~m}$ each), and 2 end-pockets (0.5 m each; Guo et al. 2012). The stretched mesh size was $0.4 \mathrm{~cm}$. Five and 3 sites were sampled in the littoral and the profundal habitat, respectively (details in Guo et al. 2012). At each sampling site, 8 nets were deployed separately with a stone in each end of the nets. After $24 \mathrm{~h}$, the catches in the end pockets were collected and identified to the species level, counted, and batch-weighed. In each month, all $R$. cliffordpopei and $R$. giurinus in the same habitat were pooled, and then sub-samples were taken for GCA and SIA. The samples for GCA were preserved in $8 \%$ formalin for $2 \mathrm{wk}$ and then transferred to $75 \%$ ethanol for storage while the samples for SIA were stored at $-20^{\circ} \mathrm{C}$.

\section{Gut content analyses}

Total body length $\left(\mathrm{L}_{\mathrm{T}}\right)$ and body mass $\left(\mathrm{M}_{\mathrm{T}}\right)$ of each specimen analyzed for GCA were measured to the nearest $\mathrm{mm}$ and $0.01 \mathrm{~g}$. Since there was no clear stomach structure for the 2 species, the foreguts (i.e. section of intestine from the esophagus to the posterior end of the first loop) were removed and preserved in $75 \%$ ethanol (Xie et al. 2000, 2005). Food items in non-empty foreguts ( $77.8 \%$ of the foreguts) were counted individually in a counting chamber and subsequently identified to the lowest possible taxonomic level under a dissecting microscope. To determine the percentage of weight of diet items, the weight of each food category was estimated. Following Chen (1981) and Zhang (2005), the estimated mean weight of Cladocera and Ostracoda was set at $0.023 \mathrm{mg}$ ind..$^{-1}$, and the estimated mean weight of Copepoda and copepod larvae was set at 0.014 and $0.003 \mathrm{mg}$ ind..$^{-1}$, respectively. The indirect volumetric analysis was used to estimate the volume of fish eggs, plant materials, and unidentified items (Hyslop 1980). The weight of these items was estimated as equal to their volume (specific gravity was assumed to be 1). After removing surface ethanol by blotting on tissue paper, shrimp larvae, aquatic insects, Gastropoda, and fish larvae were weighed to the nearest $0.1 \mathrm{mg}$ (Hyslop 1980). For each food category, frequency of occurrence (FO), percentage of number (PN), and percentage of weight (PW) were calculated using the following formulas:

$$
\mathrm{FO}_{i}=100 \mathrm{O}_{i} / \sum_{1}^{n} \mathrm{O}_{i}
$$

where $\mathrm{O}_{i}$ is the number of the guts that contain food category $i$, and $n$ is the number of individuals used for gut content analysis,

$$
\mathrm{PN}_{i}=100 \mathrm{~N}_{i} / \sum_{1}^{n} \mathrm{~N}_{i}
$$

where $\mathrm{N}_{i}$ is the number of an individual food category $i, n$ is the total number of food categories identified in all guts and

$$
\mathrm{PW}_{i}=100 \mathrm{~W}_{i} / \sum_{1}^{n} \mathrm{~W}_{i}
$$

where $\mathrm{W}_{i}$ is the weight of food category $i, n$ is the total number of food categories identified in all guts (Hyslop 1980). Finally, diet compositions of the 2 goby species were estimated using an index of relative importance (\%IRI) that was calculated using the formula:

$$
\% \mathrm{IRI}=100 \mathrm{IRI}_{i} / \sum_{1}^{n} \mathrm{IRI}_{i}
$$

where $\mathrm{IRI}_{i}=\left(\mathrm{PN}_{i}+\mathrm{PW}_{i}\right) / \mathrm{FO}_{i}, n$ is the total number of food categories identified in all guts (Assis 1996). $\mathrm{FO}, \mathrm{PN}, \mathrm{PW}$, and $\% \mathrm{IRI}_{i}$ were calculated at the individual level for each life-history stage of each species.

Based on macroscopic characteristics of gonads (Guo et al. 2013), specimens of the 2 species used for GCA were grouped into 3 life-history stages, i.e. juveniles (gonads are indistinguishable to the naked eye), sub-adults (gonads are in stages II to III), and adults (gonads are in stages IV to V). In the littoral habitat, $\mathrm{L}_{\mathrm{T}}$ (mean $\pm \mathrm{SD}, \mathrm{mm}$ ) of juvenile, sub-adult, and adult Rhinogobius cliffordpopei were $14.7 \pm 3.1$ $(\mathrm{n}=27), 27.4 \pm 3.9(\mathrm{n}=35)$, and $41.3 \pm 6.2(\mathrm{n}=41)$, respectively. $\mathrm{L}_{\mathrm{T}}$ of juvenile, sub-adult, and adult $R$. giurinus were $15.4 \pm 3.4(\mathrm{n}=34), 36.1 \pm 2.9(\mathrm{n}=42)$, and $50.4 \pm 6.4(\mathrm{n}=49)$. In the profundal habitat, $\mathrm{L}_{\mathrm{T}}$ of juvenile, sub-adult, and adult $R$. cliffordpopei were $15.1 \pm 2.5(\mathrm{n}=29), 29.9 \pm 3.1(\mathrm{n}=25)$, and $43.1 \pm 5.6$ ( $\mathrm{n}=41) . \mathrm{L}_{\mathrm{T}}$ of juvenile, sub-adult, and adult $R$. giurinus were $14.9 \pm 3.2(\mathrm{n}=37), 37.3 \pm 5.7(\mathrm{n}=33)$, and $53.4 \pm 4.7(\mathrm{n}=30)$.

\section{Stable isotope analyses}

To determine the stable isotope values of potential food resources in each habitat, macrozooplankton, Tubificidae, aquatic insects, and shrimp larvae were collected in May 2010. Macrozooplankton were collected with hand nets (standardized mesh size $64 \mu \mathrm{m}$ ) and counted under a dissecting microscope. Tubificidae and aquatic insects were sampled using a Peterson dredge (1/16 $\mathrm{m}^{2}$; details in Guo et al. 2012). Macrozooplankton included Cladocera (dominated by Daphniidae, Chydoridae, and Bosminidae) and Copepoda (dominated by Cyclopoida). Tubificidae were dominated by Limnodrilus, and aquatic insects 
were dominated by Chironomidae. Shrimp larvae were collected in benthic fyke nets and were dominated by Atyidae $\left(\mathrm{L}_{\mathrm{T}}\right.$ was $8.4 \pm 5.1 \mathrm{~mm}$, mean $\left.\pm \mathrm{SD}\right)$. Macrozooplankton, Tubificidae, and aquatic insects were kept alive in distilled water for $24 \mathrm{~h}$ for gut clearance.

Total body length $\left(\mathrm{L}_{\mathrm{T}}\right)$ and body mass $\left(\mathrm{M}_{\mathrm{T}}\right)$ of each fish used for SIA were measured to the nearest $\mathrm{mm}$ and $0.01 \mathrm{~g}$. The same amount of dorsal muscle from each individual goby and from shrimp larvae were collected for SIA. Dorsal muscle tissue of individuals with similar $\mathrm{L}_{\mathrm{T}}$ were pooled to obtain enough tissue, pooled samples included 5 to 17 individuals. The dorsal muscle samples and potential prey (i.e. macrozooplankton, Tubificidae, aquatic insects, and dorsal muscle shrimp larvae) were oven-dried at $60^{\circ} \mathrm{C}$ for $48 \mathrm{~h}$ and ground into homogeneous powder using a mortar and pestle. SIA was performed using an elemental analyzer (Flash EA1112 HT) along with an isotope ratio mass spectrometer (DELTA V Advantage, Thermo Fisher Scientific). Isotope ratios are reported using delta notation $(\delta)$ as per international standards: Pee Dee belemnite (PDB) for $\delta^{13} \mathrm{C}$ and atmospheric nitrogen for $\delta^{15} \mathrm{~N}$. Standard deviation (SD) of replicated samples was less than $0.1 \%$ for $\delta^{13} \mathrm{C}$ and $0.2 \%$ for $\delta^{15} \mathrm{~N}$. In the littoral habitat, $\mathrm{L}_{\mathrm{T}}$ (mean $\pm \mathrm{SD}$, $\mathrm{mm}$ ) of juvenile, sub-adult, and adult Rhinogobius cliffordpopei were $13.1 \pm 4.0(\mathrm{n}=10), 32.9 \pm 3.6(\mathrm{n}=$ $12)$, and $41.8 \pm 5.7(\mathrm{n}=13)$, respectively. $\mathrm{L}_{\mathrm{T}}$ of juvenile, sub-adult, and adult $R$. giurinus were $14.4 \pm 3.3$ $(\mathrm{n}=14), 35.5 \pm 4.5(\mathrm{n}=24)$, and $52.1 \pm 8.4(\mathrm{n}=16)$. In the profundal habitat, $\mathrm{L}_{\mathrm{T}}$ of juvenile, sub-adult, and adult $R$. cliffordpopei were $13.6 \pm 4.8(\mathrm{n}=12), 30.2 \pm$ $4.8(\mathrm{n}=13)$, and $44.1 \pm 6.4(\mathrm{n}=10) . \mathrm{L}_{\mathrm{T}}$ of juvenile, sub-adult, and adult $R$. giurinus were $14.2 \pm 3.6$ ( $\mathrm{n}=$ $10), 37.5 \pm 6.4(\mathrm{n}=20)$, and $54.8 \pm 8.5(\mathrm{n}=21)$.

\section{Statistical analyses}

Chi-squared $\left(\chi^{2}\right)$ tests were used to test for differences in diet compositions (\%IRI) between lifehistory stages (juveniles, sub-adults, and adults) within species, between species (Rhinogobius cliffordpopei and R. giurinus), and habitats (littoral and profundal) within the same life-history stage (Gallagher \& Dick 2011). The dietary niche breadth of each life stage of each species was estimated using the niche breadth $(B)$ of Levins (1968):

$$
B=1 / \sum_{1}^{n} P_{i}^{2}
$$

where $P_{i}$ is the frequency of occurrence of prey item $i$ in the diet of a consumer, and $n$ is the number of prey groups. $B$ values increase with dietary niche breadth. Moreover, Pianka's (1973) index (O) was used to determine trophic niche overlap between life-history stages in each species, between species at the same life stage within a habitat, and between habitats at the same life stage in each species. $O$ was calculated as:

$$
O_{j k}=\sum_{1}^{n} P_{i j} P_{i k} /\left(\sum_{1}^{n} P_{i j}^{2} \sum_{1}^{n} P_{i k}^{2}\right)^{1 / 2}
$$

where $P_{i}$ is the frequency of occurrence of prey items $i$ in the diet of species $j$ and $k$, and $n$ is the number of prey groups. $O$ varies between 0 (total separation) and 1 (total overlap). A modification of the graphical Costello method was used to illustrate feeding strategy of the 2 species (Amundsen et al. 1996). The analysis is based on a 2-dimensional representation of prey-specific abundance $\left(\mathrm{P}_{i}\right)$ and frequency of occurrence $(\% \mathrm{O})$ of the different prey types in the diet.

$$
\mathrm{P}_{i}=\left(\sum_{1}^{n} S_{i} / \sum_{1}^{n} S t_{i}\right)
$$

where $\mathrm{P}_{i}$ is the prey-specific abundance of prey $i, S_{i}$ is the stomach content (number) comprised of prey $i$, and $S t_{i}$ is the total stomach content in only those predators with prey $i$ in their stomach (Amundsen et al. 1996).

After examination of normality and variance homogeneity of the data using Kolmogorov-Smirnov and Levene's tests, 3-way ANOVAs were used to test for differences in stable isotope values $\left(\delta^{13} \mathrm{C}\right.$ and $\delta^{15} \mathrm{~N}$ were inverse-transformed and tested separately) between life-history stages, species, and habitats. If species and/or habitats had a significant effect on the isotope values of fish, Mann-Whitney tests were then used to test for differences in stable isotope values between species within habitats and/or between habitats within species at the same life-history stage. The relative contribution of each potential prey to the diet of the 2 species and different life stages was estimated using stable isotope mixing models, i.e. Stable Isotope Analysis in R (SIAR, http://cran.r-project.org/ web/packages/siar/; Inger et al. 2010). Since there were no available trophic fractionation factor (TFF) values for the 2 goby species, we used an average TFF with a large SD as suggested by Inger et al. (2010). Specifically, we used TFFs of $1.0 \pm 1.0 \%$ o (mean $\pm \mathrm{SD}$ ) for $\delta^{13} \mathrm{C}$ and $3.3 \pm 1.0 \%$ for $\delta^{15} \mathrm{~N}$ (e.g. Inger et al. 2010). Mean $\delta^{13} \mathrm{C}$ and $\delta^{15} \mathrm{~N}$ values $( \pm \mathrm{SD}, \mathrm{n}=$ 3 ) of potential prey in each habitat were used in the models. As life-history stages and habitats significantly affected the values of $\delta^{13} \mathrm{C}$ and $\delta^{15} \mathrm{~N}$ (see 'Results'), the models were run separately for the differ- 
ent life-history stages in each habitat. All statistical analyses were conducted in R 2.14.2 (R Development Core Team 2012).

\section{RESULTS \\ Ontogenetic trophic niche shifts}

In each habitat, juveniles of the 2 species showed significantly different diet compositions (\%IRI) compared to sub-adults and adults $\left(\chi^{2}\right.$ test, $\left.\mathrm{p}<0.05\right)$, whereas the diet compositions of sub-adults and adults did not differ significantly $\left(\chi^{2}\right.$ test, $\mathrm{p}>0.05$, Table 1, Fig. 1). Specifically, \%IRI of macrozooplankton was $71.0 \%$ in littoral habitat and $59.4 \%$ in profundal habitat for juveniles of Rhinogobius cliffordpopei, and $67.7 \%$ in littoral habitat and $55.4 \%$ in profundal habitat for juveniles of $R$. giurinus (Fig. 1). It decreased significantly at the sub-adult and adult life-stages for the 2 species in each habitat (Fig. 1). In both habitats, \%IRI of aquatic insects was less than $9.3 \%$ for juveniles of the 2 gobies, whereas it increased to 20.4-33.3\% (R. cliffordpopei) and 39.1$55.7 \%$ ( $R$. giurinus) for sub-adults, 30.6-50.6\% ( $R$. cliffordpopei) and 49.1-61.3\% ( $R$. giurinus) for adults (Fig.1). In both habitats, juveniles of each the species showed the lowest Levin's niche breadth $(B)$ (0.240.27 for $R$. cliffordpopei and $0.23-0.28$ for $R$. giurinus), whereas $B$ values were higher for sub-adults (0.35-0.48 for $R$. cliffordpopei and 0.48-0.50 for $R$. giurinus) and adults (0.41-0.47 for $R$. cliffordpopei and $0.48-0.50$ for $R$. giurinus) (Fig. 2). Pianka's index $(O)$ between juveniles and adults was the lowest in the 2 habitats for each species $(0.76-0.83$ for $R$. cliffordpopei and 0.73-0.80 for $R$. giurinus), while subadults and adults showed higher $O$ values (0.80-0.97 for $R$. cliffordpopei and 0.03-0.97 for $R$. giurinus) (Fig. 3). Based on the feeding strategy diagram (Fig. 4), no clear specialization towards a single prey type was observed in either species (Fig. 4). Thus the 2 gobies primarily showed a generalized or mixed feeding strategy, with varying degrees of specialization and generalization on different prey types.

Life-history stages had significant effects on $\delta^{13} \mathrm{C}$ and $\delta^{15} \mathrm{~N}$ values (3-way ANOVA, p < 0.001, Table 2).

Fig. 1. Rhinogobius cliffordpopei $(R C)$ and $R$. giurinus $(R G)$. Diet compositions (index of relative importance, \%IRI) of 2 goby species at 3 life-history stages (juveniles, sub-adults, and adults) in (A) littoral habitat and (B) profundal habitat of Lake Erhai (China) in 2010
Table 1. Rhinogobius cliffordpopei and $R$. giurinus. Differences $\left(\chi^{2}\right.$ tests) in diet compositions (index of relative importance, \%IRI) of 2 goby species between life-history stages (juveniles, sub-adults, and adults) within species in littoral and profundal habitats of Lake Erhai (China) in 2010; df $=9$ in all cases

\begin{tabular}{|llrrrr|}
\hline \multirow{2}{*}{ Species } & Life-history & \multicolumn{2}{c}{ Juveniles } & \multicolumn{2}{c|}{ Sub-adults } \\
& stage & $\chi^{2}$ & $\mathrm{p}$ & $\chi^{2}$ & $\mathrm{p}$ \\
\hline Littoral & & & & & \\
R. cliffordpopei & Sub-adults & 21.09 & 0.012 & & \\
& Adults & 38.04 & $<0.001$ & 9.98 & 0.352 \\
R. giurinus & Sub-adults & 33.47 & $<0.001$ & & \\
& Adults & 47.73 & $<0.001$ & 11.59 & 0.237 \\
& & & & & \\
Profundal & & & & & \\
R. cliffordpopei & Sub-adults & 33.47 & $<0.001$ & & \\
& Adults & 47.72 & $<0.001$ & 16.35 & 0.060 \\
R. giurinus & Sub-adults & 66.15 & $<0.001$ & & \\
& Adults & 79.73 & $<0.001$ & 15.96 & 0.068 \\
& & & & & \\
\hline
\end{tabular}
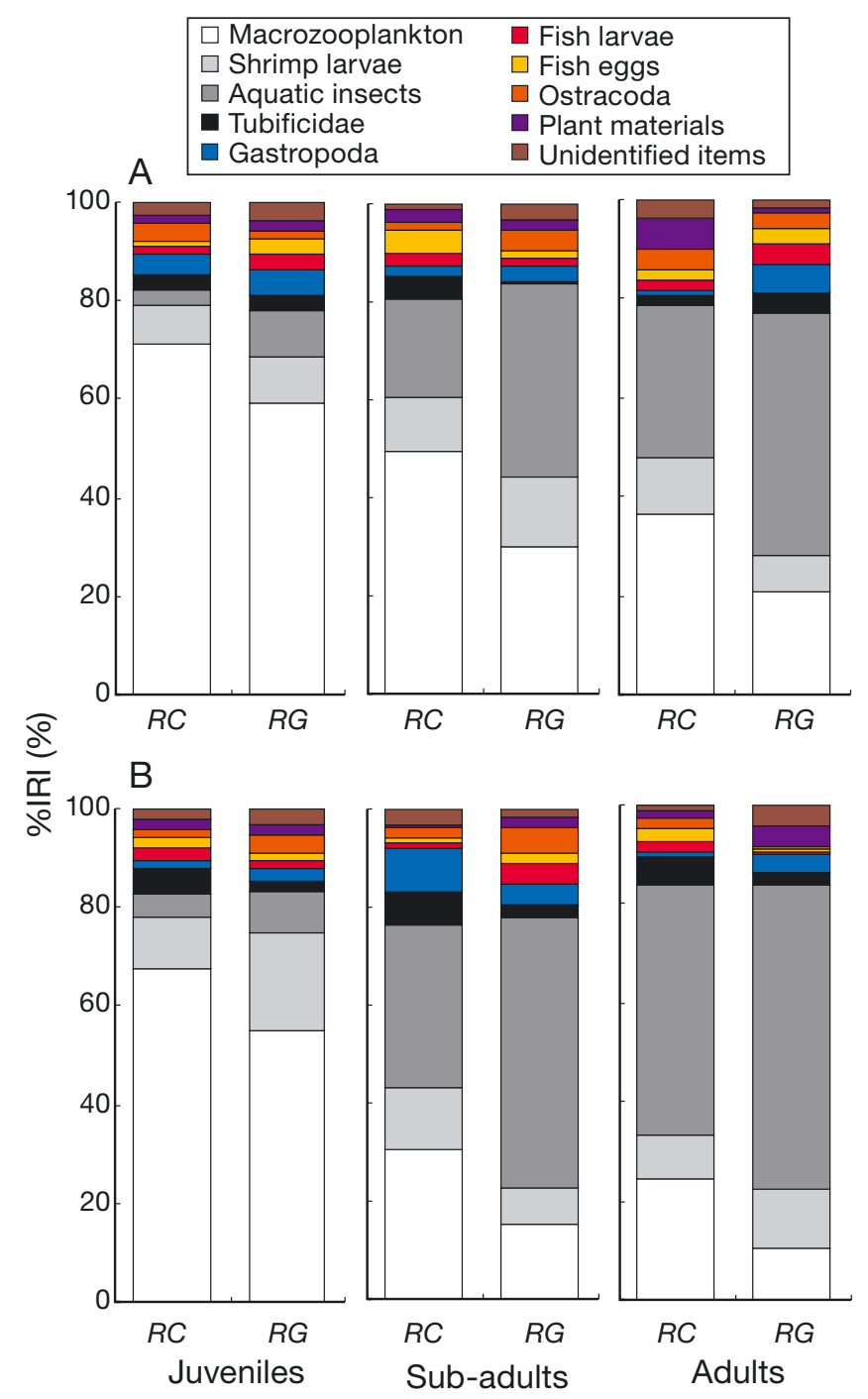


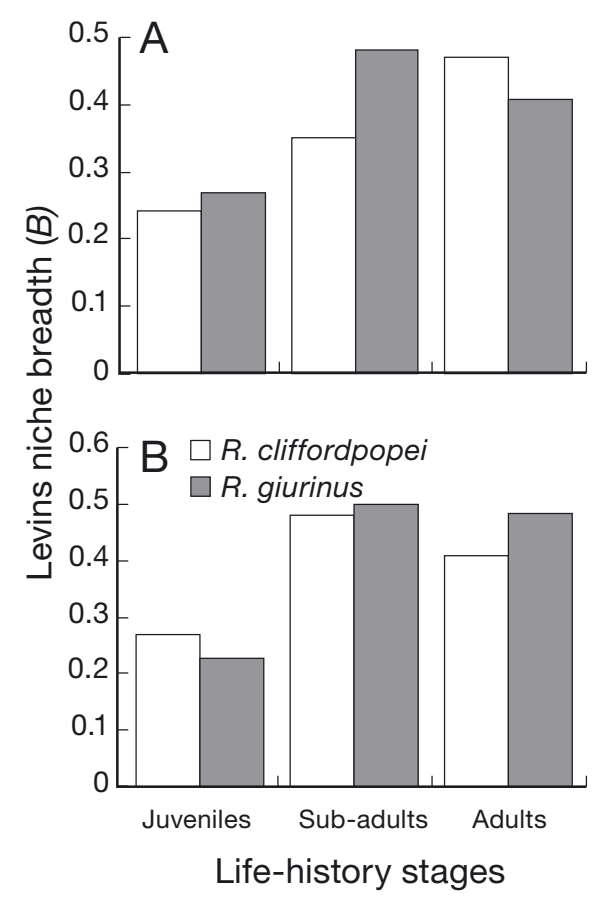

Fig. 2. Rhinogobius cliffordpopei and R. giurinus. Levin's niche breadth $(B)$ of juveniles, sub-adults, and adults of 2 goby species in (A) littoral habitat and (B) profundal habitat of Lake Erhai (China) in 2010

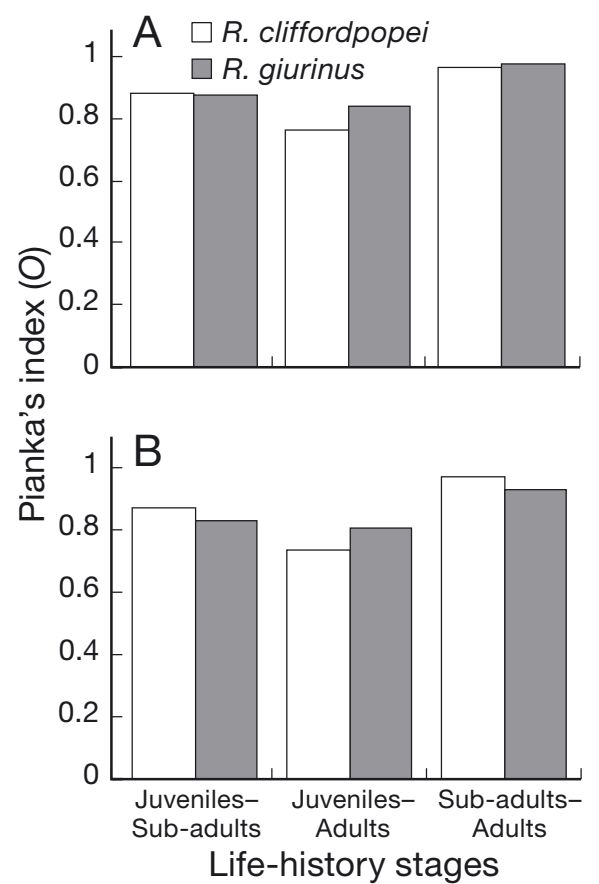

Fig. 3. Rhinogobius cliffordpopei and R. giurinus. Pianka's index $(O)$ between juveniles and sub-adults, between juveniles and adults, and between sub-adults and adults of 2 goby species in (A) littoral habitat and (B) profundal habitat of Lake Erhai (China) in 2010
Both species generally showed more enriched $\delta^{13} \mathrm{C}$ and $\delta^{15} \mathrm{~N}$ values for juveniles compared to adults in the 2 habitats (Fig. 5). The mixing models estimated that the contribution of macrozooplankton was one order of magnitude higher for juveniles (43.4-74.1\%) than for adults $(4.2-7.4 \%)$ of the 2 species in both habitats (Fig. 5). The contribution of aquatic insects and Tubificidae to the diet of juveniles of the 2 species $(3.4-9.2 \%)$ was relatively low while they represented the main food resources of sub-adults and adults in both habitats $(27.0-53.2 \%$, Fig. 6).

\section{Trophic niche differences between species within habitats}

The diet composition (\%IRI) did not differ between juveniles (littoral: $\chi^{2}=6.07, p=0.723$; profundal: $\chi^{2}=$ $8.10, p=0.523, d f=9$ ) but was significantly different between sub-adults and between adults within habitat. Specifically, sub-adults and adults of Rhinogobius cliffordpopei preyed more on macrozooplankton than $R$. giurinus, while $R$. giurinus consumed more aquatic insects than $R$. cliffordpopei in the 2 habitats $\left(\chi^{2}=19.01, p=0.025\right.$ for sub-adults and $\chi^{2}=18.19, p=$ 0.032 for adults in littoral habitat; $\chi^{2}=22.03, p=0.008$ for sub-adults and $\chi^{2}=19.19, \mathrm{p}=0.024$ for adults in profundal habitat, $\mathrm{df}=9$; Fig. 1). Pianka's index $(O)$ of juveniles between the 2 species was the highest $(0.95$ in littoral, 0.97 in profundal), followed by adults ( 0.88 in littoral, 0.87 in profundal) and sub-adults (0.84 in littoral, 0.86 in profundal) (Fig. 3).

$\delta^{13} \mathrm{C}$ and $\delta^{15} \mathrm{~N}$ values differed significantly between the 2 species in both habitats (3-way ANOVA, p < 0.05 , Table 2). In the littoral habitat, stable isotope values of juveniles did not differ significantly between species (Mann-Whitney tests, $p=0.289$ in $\delta^{13} \mathrm{C}$ and $\mathrm{p}=0.239$ in $\delta^{15} \mathrm{~N}$ ), while sub-adults of Rhinogobius cliffordpopei showed significantly enriched $\delta^{13} \mathrm{C}$ (Mann-Whitney tests, $\mathrm{p}<0.001$ ) and $\delta^{15} \mathrm{~N}$ (MannWhitney tests, $\mathrm{p}=0.003$ ) compared to $R$. giurinus (Fig. 5). Adults of $R$. cliffordpopei in the littoral habitat were significantly enriched in $\delta^{13} \mathrm{C}$ (MannWhitney tests, $\mathrm{p}=0.010$ ) but significantly more depleted in $\delta^{15} \mathrm{~N}$ (Mann-Whitney tests, $\mathrm{p}=0.015$ ) than $R$. giurinus (Fig. 5). In the littoral habitat, mixing models predicted that macrozooplankton and shrimp larvae contributed more to the diets of sub-adult $R$. cliffordpopei than $R$. giurinus, whereas aquatic insects and Tubificidae contributed more to the diets of sub-adult $R$. giurinus than $R$. cliffordpopei (Fig. 6). For adults in this habitat, $R$. cliffordpopei consumed fewer aquatic insects but more Tubificidae than $R$. 


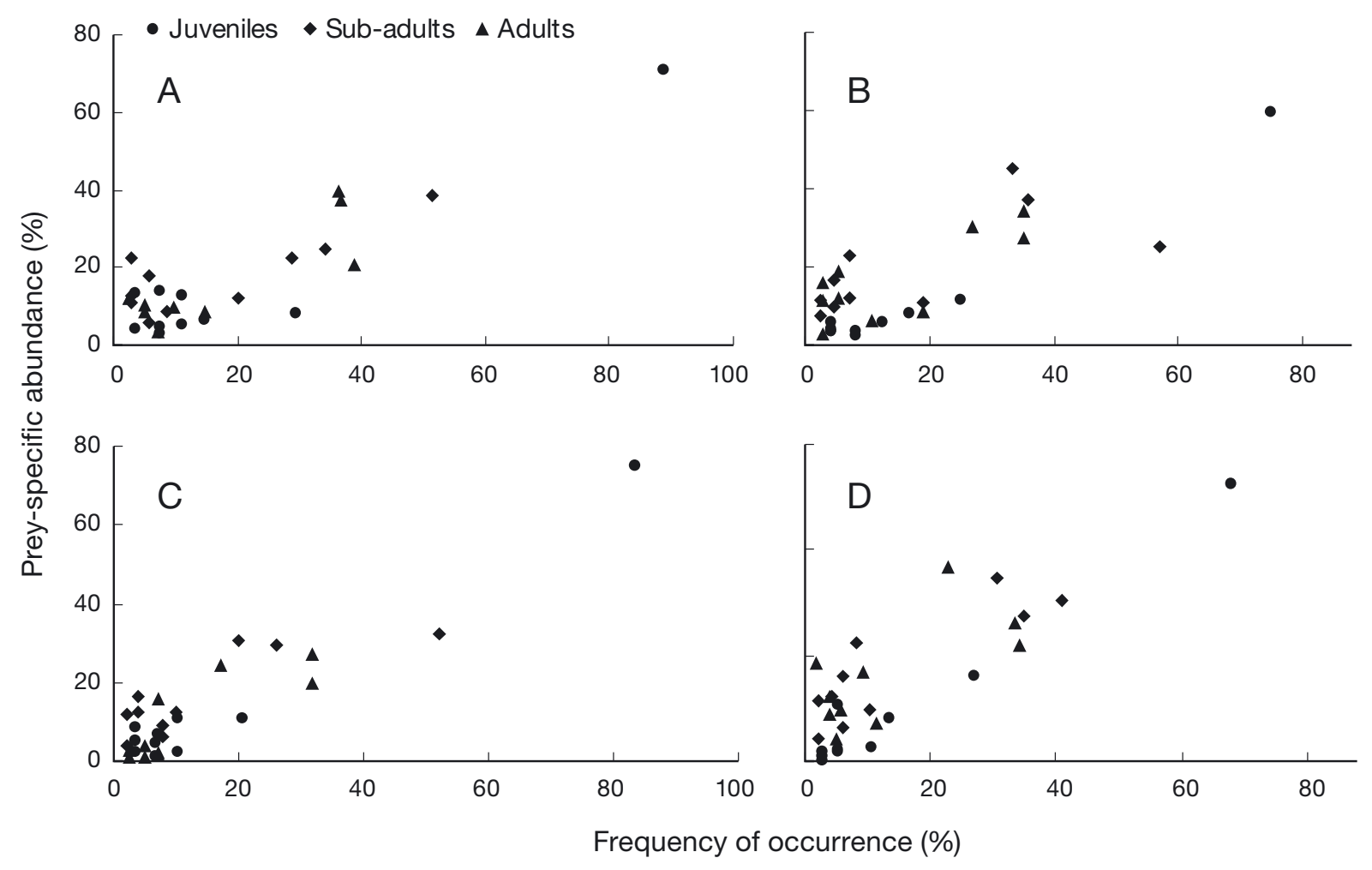

Fig. 4. Rhinogobius cliffordpopei and R. giurinus. Feeding strategy diagrams based on the Costello method: prey-specific abundance plotted against frequency of occurrence of prey in the diet of 2 goby species in Lake Erhai (China). (A) $R$. cliffordpopei in littoral habitat, (B) R. giurinus in littoral habitat, (C) R. cliffordpopei in profundal habitat, (D) $R$. giurinus in profundal habitat

Table 2. Rhinogobius cliffordpopei and $R$. giurinus. Differences (3-way ANOVAs) in stable isotope values $\left(\delta^{13} \mathrm{C}\right.$ and $\delta^{15} \mathrm{~N}$, inverse-transformed) between life-history stages (juveniles, sub-adults, and adults), species, and habitats (littoral and profundal) in Lake Erhai (China) in 2010

\begin{tabular}{|lrrr|}
\hline Source & df & \multicolumn{1}{c|}{$F$} & $\mathrm{p}$ \\
\hline $\boldsymbol{\delta}^{\mathbf{1 3}} \mathbf{C}(\%)$ & & & \\
Life-history stage & 2 & 321.63 & $<0.001$ \\
Species & 1 & 21.73 & $<0.001$ \\
Habitat & 1 & 50.48 & $<0.001$ \\
Life-history stage $\times$ Species & 2 & 0.31 & 0.730 \\
Life-history stage $\times$ Habitat & 2 & 0.46 & 0.230 \\
Species $\times$ Habitat & 1 & 7.24 & 0.008 \\
Life-history stage $\times$ Species $\times$ Habitat & 2 & 2.26 & 0.111 \\
Residuals & 158 & & \\
& & & \\
$\boldsymbol{\delta}^{\mathbf{1 5}} \mathbf{N}(\%)$ & & & \\
Life-history stage & 2 & 59.43 & $<0.001$ \\
Species & 1 & 7.23 & 0.008 \\
Habitat & 1 & 301.98 & $<0.001$ \\
Life-history stage $\times$ Species & 2 & 0.67 & 0.510 \\
Life-history stage $\times$ Habitat & 2 & 1.62 & 0.204 \\
Species $\times$ Habitat & 1 & 11.79 & $<0.001$ \\
Life-history stage $\times$ Species $\times$ Habitat & 2 & 0.29 & 0.750 \\
Residuals & 158 & & \\
\hline
\end{tabular}

giurinus. In the profundal habitat, the 2 species showed similar $\delta^{13} \mathrm{C}$ and $\delta^{15} \mathrm{~N}$ values at each life-history stage (Mann-Whitney tests, $\mathrm{p}=0.640,0.341$, and 0.229 in $\delta^{13} \mathrm{C}$, and $\mathrm{p}=0.634,0.435$, and 0.353 in $\delta^{15} \mathrm{~N}$ for juveniles, sub-adults, and adults, respectively; Figs. 5 \& 6).

\section{Trophic niche differences between habitats within species}

Diet composition (\%IRI) of each of the 2 species was similar between habitats for juveniles $\left(\chi^{2}=2.89\right.$, $\mathrm{p}=0.968$ for Rhinogobius cliffordpopei and $\chi^{2}=6.56$, $\mathrm{p}=0.682$ for $R$. giurinus, $\mathrm{df}=9$ ), but it was significantly different for sub-adults $\left(\chi^{2}=18.15, \mathrm{p}=0.033\right.$ for $R$. cliffordpopei and $\chi^{2}=19.75, \mathrm{p}=0.020$ for $R$. giurinus, $\mathrm{df}=9)$ and adults of each species $\left(\chi^{2}=\right.$ 18.78, $\mathrm{p}=0.027$ for $R$. cliffordpopei and $\chi^{2}=19.26, \mathrm{p}=$ 0.023 for $R$. giurinus, $\mathrm{df}=9$ ) (Fig. 1). Indeed, subadults and adults of each species generally consumed more macrozooplankton and fewer aquatic insects in littoral habitat than in profundal habitat (Fig. 1). Juveniles of each species showed the highest 


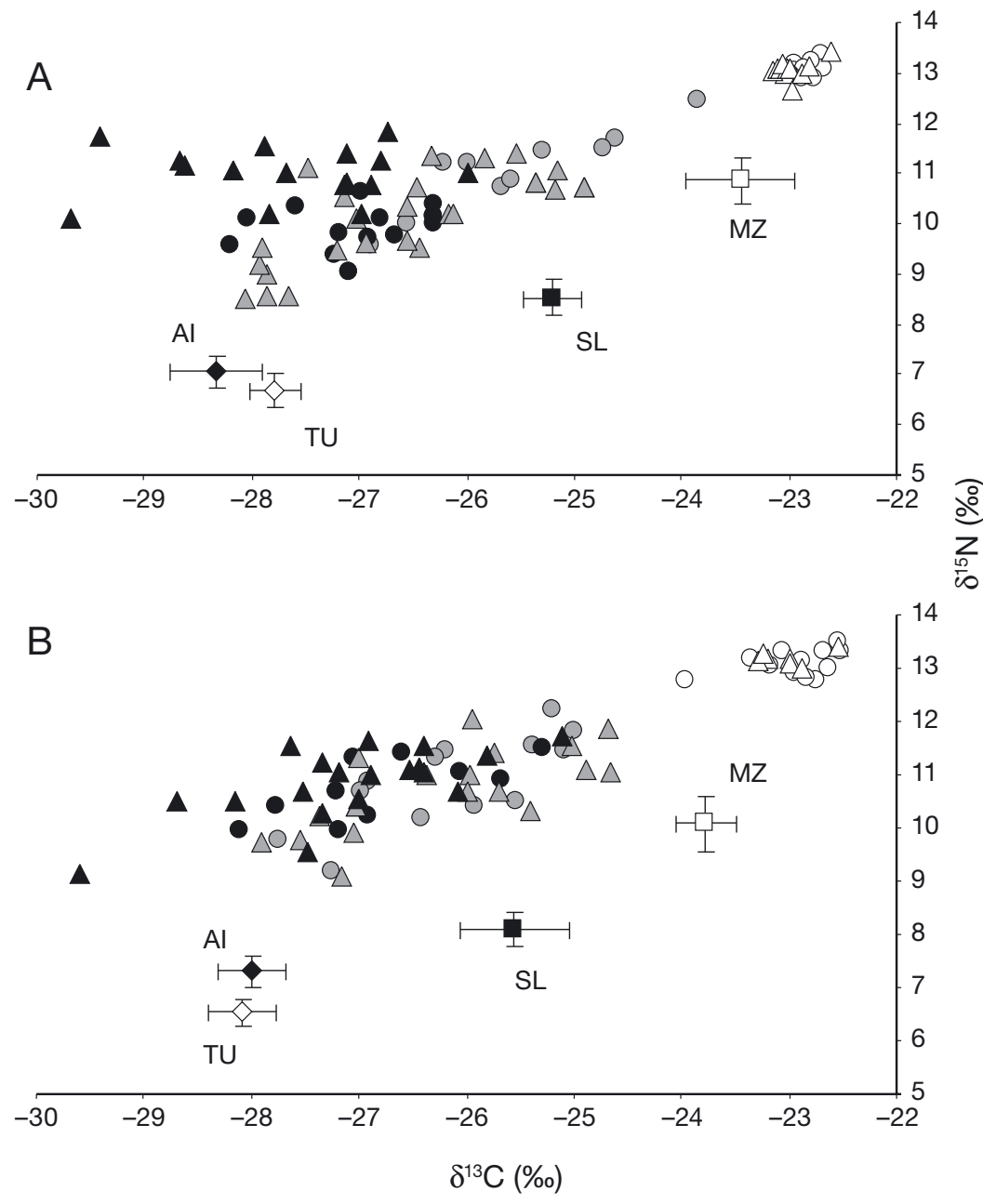

Fig. 5. Rhinogobius cliffordpopei and $R$. giurinus. Stable isotope values $\left(\delta^{13} \mathrm{C}\right.$ and $\delta^{15} \mathrm{~N}, \%$ ) of $R$. cliffordpopei (circles), $R$. giurinus (triangles), and their potential food resources (mean $\pm \mathrm{SD}, \mathrm{n}=3$ ) in (A) littoral habitat and (B) profundal habitat of Lake Erhai (China) in 2010. Juveniles, sub-adults, and adults are displayed with white, grey, and black symbols, respectively. Potential food resources were macrozooplankton (MZ), shrimp larvae (SL), aquatic insects (AI), and Tubificidae (TU)

Pianka's index $(O)$ between habitats $(0.96$ for $R$. cliffordpopei and 0.92 for $R$. giurinus). The $O$ values of sub-adults and adults ranged from 0.79 to 0.88 between habitats (sub-adults: 0.83 for $R$. cliffordpopei and 0.88 for $R$. giurinus; adults: 0.79 for $R$. cliffordpopei and 0.86 for $R$. giurinus, Fig. 3 ).

Stable isotope values of the 2 species differed significantly between habitats (3-way ANOVA, p < 0.001 , Table 2). Specifically, sub-adults and adults of Rhinogobius giurinus displayed significantly enriched $\delta^{13} \mathrm{C}$ (Mann-Whitney tests, $\mathrm{p}<0.001$ ) and depleted $\delta^{15} \mathrm{~N}$ (Mann-Whitney tests, $\mathrm{p}<0.001$ ) values in littoral habitat compared to profundal habitat, whereas $\delta^{13} \mathrm{C}$ and $\delta^{15} \mathrm{~N}$ of $R$. cliffordpopei were similar for the 3 life-history stages between habitats
(Mann-Whitney tests, $\mathrm{p}=0.154,0.245$, and 0.378 in $\delta^{13} \mathrm{C}$ and $\mathrm{p}=0.093,0.356$, and 0.289 in $\delta^{15} \mathrm{~N}$ for juveniles, subadults, and adults, respectively) (Fig. 5). The mixing models predicted that subadults and adults of $R$. giurinus consumed more aquatic insects and fewer Tubificidae in littoral habitat than in profundal habitat. The contribution of macrozooplankton and shrimp larvae to the diet of each species was similar between habitats (Fig. 6). For R. cliffordpopei, the dietary contribution of the different prey did not differ between the 2 habitats (Fig. 6).

\section{DISCUSSION}

Macrozooplankton (Cladocera and Copepoda) were the main prey consumed by juveniles and were also an important food resource for sub-adults of the 2 goby species in the 2 habitats of Lake Erhai (Figs. 1 \& 5). Our results are consistent with findings in lakes along the middle and lower reaches of the Yangtze River, including Liangzi Lake (Xie et al. 2005) and Biandantang Lake (Xie et al. 2000, Zhang 2005), where the 2 species are native. Both gobies shifted their diet by feeding increasingly on macrozoobenthos as they grew. Most goby species mainly consume macrozoobenthos when they settle on lake bottoms after their initial pelagic lifehistory stages (Kakareko et al. 2005, Borza et al. 2009, Grabowska et al. 2009). Of the macrozoobenthos, chironomid larvae are among the main prey consumed by species belonging to the genus Rhinogobius (Zhang 2005, Rusuwa et al. 2009). The estimated contribution of Tubificidae to the diet of sub-adults and adults was higher when using SIA than with GCA. These differences could be caused by the high digestibility and low detectability of Tubificidae in GCA, which do not affect estimates based on SIA (Inger et al. 2010, Polito et al. 2011, Cucherousset et al. 2012). In the present study, the trophic niche of the 2 goby species showed a strong ontogenetic diet shift from macrozooplankton to aquatic insects and Tubificidae. A similar shift has been observed for $R$. brunneus in the Ado River of Japan, where the 3 most important food items were 


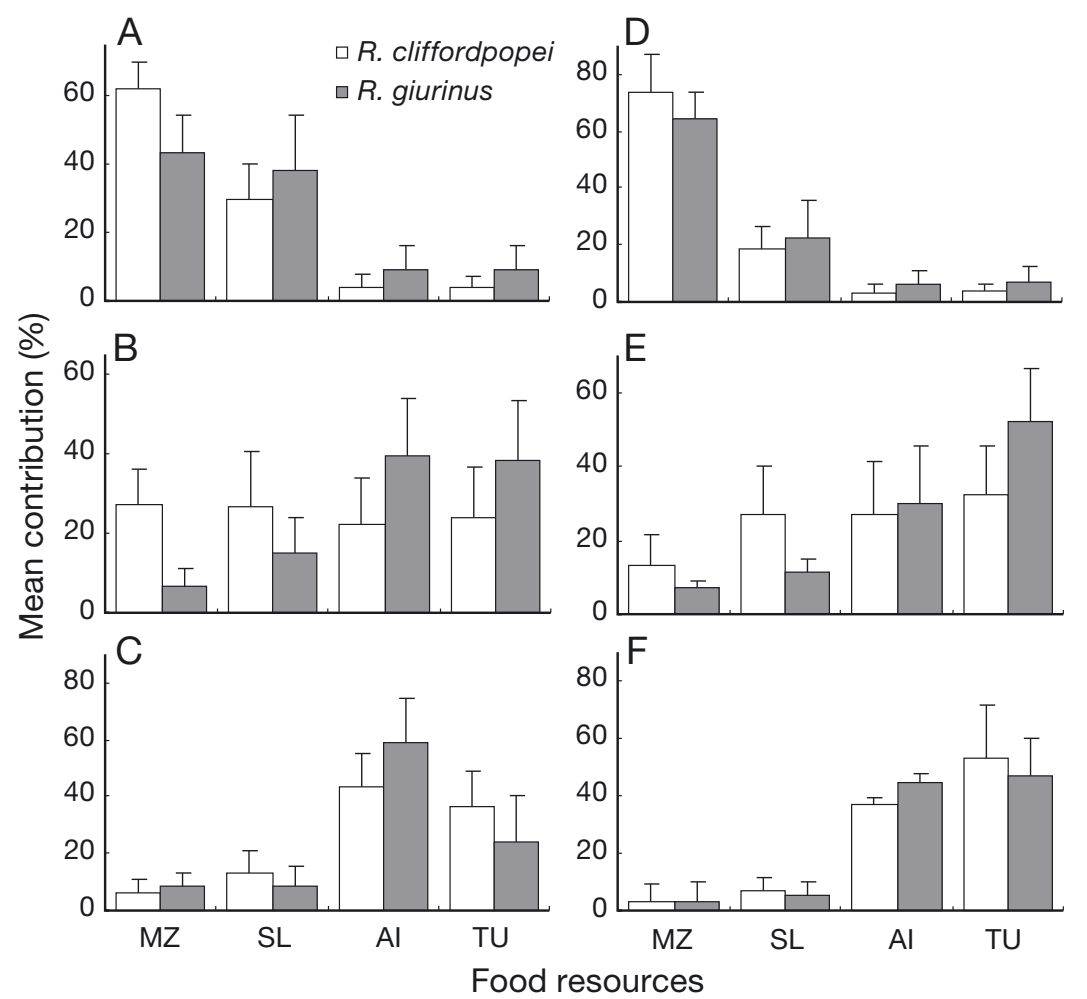

Fig. 6. Rhinogobius cliffordpopei and R. giurinus. Estimated relative contribution (mean $\pm \mathrm{SD}$ ) of potential food resources to the diets of 2 goby species in littoral habitat (A: juveniles, B: sub-adults, C: adults) and profundal habitat (D: juveniles, E: sub-adults, F: adults) of Lake Erhai (China) in 2010. Potential food resources were macrozooplankton (MZ), shrimp larvae (SL), aquatic insects (AI), and Tubificidae (TU). Values were estimated using stable isotope mixing models (Stable Isotope Analyses in R package)

Ephemeroptera, Diptera, and Cyanophyta for juveniles and Ephemeroptera, Trichoptera, and detritus for adults (Rusuwa et al. 2009). Moreover, we found that $\delta^{15} \mathrm{~N}$ decreased from juveniles to adults. This pattern was driven by the fact that Cladocera and Copepoda (i.e. main diets of juveniles) had higher $\delta^{15} \mathrm{~N}$ than aquatic insects and Tubificidae (i.e. main diets of adults). Generally, phytoplankton is the primary resource of zooplankton (Pietrzak et al. 2010, Yin et al. 2010). Aquatic insects and Tubificidae consume mostly detritus (e.g. leaf litter) and/or periphyton (e.g. particulate organic matter, POM; Füreder et al. 2003, Compson et al. 2013). Several studies have observed that algae could have more enriched $\delta^{15} \mathrm{~N}$ values than detritus or POM (France \& Schlaepfer 2000, Vizzini et al. 2002, Bunn et al. 2003), as these primary producers represent 2 different food chains. Potential higher $\delta^{15} \mathrm{~N}$ values of primary producers in Lake Erhai were therefore likely to lead to higher $\delta^{15} \mathrm{~N}$ values in zooplankton compared to aquatic insects and Tubificidae, and thus to the observed decrease in $\delta^{15} \mathrm{~N}$ during ontogeny of the 2 goby species.
In the littoral habitat, juveniles of the 2 gobies showed a similar trophic niche while sub-adults and adults displayed different trophic niches. Body size has a strong influence on trophic niche since it affects foraging efficiency (e.g. gape size) and/or competitive ability (Colloca et al. 2010, Nakayama \& Fuiman 2010, Wasserman 2012). Since small individuals are gape-limited and are almost exclusively zooplanktivorous in the pelagic habitat, the competing fishes at this life-history stage rarely show clear trophic niche specialization (Colloca et al. 2010, Nakayama \& Fuiman 2010, Rodrigues \& Vieira 2010). Sub-adults or adults (larger-sized individuals) usually have better locomotion capacity and higher feeding efficiency (Borcherding et al. 2010), which are associated with a broader spectrum of prey size. Therefore, these individuals can specialize and partition different food resources, which may allow species co-occurrence among closely related or ecologically similar species within a community (Colloca et al. 2010, Davis et al. 2012). Several studies have demonstrated that sub-adult or adult gobies can exhibit food partitioning when they become abundant outside of their native ranges (Kakareko et al. 2005, Borcherding et al. 2013). For instance, in the Danube River (Hungary), Ponticola kessleri mainly consumed Dikerogammarus spp. while Neogobius melanostomus principally foraged on chironomid larvae in spring (Borza et al. 2009).

In the profundal habitat, SIA indicated that the trophic niche of sub-adults and adults was similar between species, whereas their diets appeared different when analyzed using GCA. GCA provides a short-term estimate of individual diets, reflecting an individual's recent feeding history, while SIA is a more integrative tool that provides longer-term dietary records (Post 2002, Polito et al. 2011, Cucherousset et al. 2012). Therefore, it is very likely that over a season of growth, sub-adults and adults of the 2 species displayed different patterns of food partitioning in the 2 habitats, with different trophic niches in littoral habitat and similar trophic niches in profundal habitat. Trophic resource use among competing fishes may vary with environmental factors in- 
cluding habitat conditions (e.g. stable versus highly variable ecosystem, Davis et al. 2012), prey availability (Shimose et al. 2010), or density of competitors (Kim \& Grant 2007, Kaspersson et al. 2010). In Lake Erhai, the 2 studied habitats are characterized by strong differences in depth, submerged macrophytes, food abundances, and density of predators (Guo et al. 2012). In addition, the abundance of Rhinogobius cliffordpopei was highest in the littoral habitat (water depth $<6 \mathrm{~m}$ ), followed by sub-littoral habitat (water depth ranging from 6 to $12 \mathrm{~m}$ ) and lowest in profundal habitat (water depth ranging from 12 to $20 \mathrm{~m}$ ), whereas the abundance of $R$. giurinus were highest in the profundal habitat, followed by sub-littoral habitat and lowest in littoral habitat (Guo et al. 2012). Density of competitors (the 2 goby species) is also an important factor that influences foraging behavior and competitive processes (Kim \& Grant 2007, Kaspersson et al. 2010). Therefore, further investigations are needed to elucidate the specific effects of those factors on the patterns of competition and food partitioning between the 2 invasive species.

Invasive gobies, in many cases, consume different diets in the face of spatial (Kakareko et al. 2005, Grabowska et al. 2009, Rusuwa et al. 2009) and temporal (e.g. seasons, Grabowska et al. 2009, Rusuwa et al. 2009; months, Borcherding et al. 2013) variation in food availability. In our study, juveniles of the 2 goby species did not exhibit clear differences in diet compositions between littoral and profundal habitats due to the high dietary contribution of zooplankton (Rodrigues \& Vieira 2010, Wasserman 2012). However, sub-adults and adults generally consumed more macrozooplankton and chironomid larvae in littoral habitat but more Tubificidae in profundal habitat. In Lake Erhai, the density of macrozooplankton and aquatic insects in littoral habitat is almost twice as high as in profundal habitat, whereas the Tubificidae are much more abundant in profundal habitat than in littoral habitat. The diets of sub-adults and adults seem to closely match the abundances of available food resources in the 2 habitats. Similar patterns were observed in Neogobius fluviatilis and N. gymnotrachelus in River Vistula of Poland (Kakareko et al. 2005).

In conclusion, the present study demonstrated that these 2 closely related species displayed a strong trophic shift during ontogeny, with juveniles of the 2 goby species showing similar trophic niches while sub-adults and adults partitioned their food resources within the same habitat. Moreover, these 2 species showed different diet composition when food avail- ability differed between habitats. Understanding the competing interactions triggering food partitioning is crucial, and further experimental investigations should examine how exploitive competition (e.g. food intake, feeding rate) or interference competition (e.g. chase rate, attack rate, food holding capacity) varies with habitat conditions (food resource levels, population densities, predation risks) and mechanistically drives trophic niche segregation.

Acknowledgements. The research was financially supported by the National Natural Science Foundation of China (No. 31172387), the Major Science and Technology Program for Water Pollution Control and Treatment of China (No. 2012ZX07105-004), and the National S\&T Supporting Program (No. 2012BAD25B08). We thank T. Pool for editorial improvements and X. Chen for technical assistance. Z.G., J.C., and S.L. are members of the lab EDB, part of the 'Laboratoire d'Excellence (LABEX) entitled TULIP (ANR-10LABX-41)'. J.C. received funding from the European Union Seventh Framework Programme (FP7/2007-2013) under grant agreement number PERG08-GA-2010-276969.

\section{LITERATURE CITED}

Amundsen PA, Gabler HM, Staldvik FJ (1996) A new approach to graphical analysis of feeding strategy from stomach contents data-modification of the Costello (1990) method. J Fish Biol 48:607-614

Assis CA (1996) A generalized index for stomach contents analysis in fish. Sci Mar 60:385-389

Borcherding J, Beeck P, DeAngelis DL, Scharf WR (2010) Match or mismatch: the influence of phenology on sizedependent life history and divergence in population structure. J Anim Ecol 79:1101-1112

Borcherding J, Dolina M, Heermann L, Knutzen P and others (2013) Feeding and niche differentiation in three invasive gobies in the Lower Rhine, Germany. Limnologica 43:49-58

Borza P, Erös T, Oertel N (2009) Food resource partitioning between two invasive gobiid species (Pisces, Gobiidae) in the littoral zone of the River Danube, Hungary. Int Rev Hydrobiol 94:609-621

> Bunn SE, Davies PM, Winning M (2003) Sources of organic carbon supporting the food web of an arid zone floodplain river. Freshw Biol 48:619-635

Chen XM (1981) Estimating biomass of freshwater copepods. Acta Hydrol Sin 7:397-408 (in Chinese with English abstract)

Chesson P (2000) Mechanisms of maintenance of species diversity. Annu Rev Ecol Syst 31:343-366

Colloca F, Carpentieri P, Balestri E, Ardizzone G (2010) Food resource partitioning in a Mediterranean demersal fish assemblage: the effect of body size and niche width. Mar Biol 157:565-574

> Compson ZG, Adams KJ, Edwards JA, Maestas JM, Whitham TG, Marks JC (2013) Leaf litter quality affects aquatic insect emergence: contrasting patterns from two foundation trees. Oecologia 173:507-519

Cucherousset J, Bouletreau S, Martino A, Roussel JM, Santoul F (2012) Using stable isotope analyses to determine 
the ecological effects of non-native fishes. Fish Manag Ecol 19:111-119

> Davis AM, Pusey BJ, Pearson RG (2012) Contrasting intraspecific dietary shifts in two terapontid assemblages from Australia's wet-dry tropics. Ecol Freshw Fish 21:42-56

Du B, Li Y (2001) Danger risk to fish diversity in Lake Erhai and proposals to dispel it. Res Environ Sci 14:42-45 (in Chinese with English abstract)

- France RL, Schlaepfer MA $(2000){ }^{13} \mathrm{C}$ and ${ }^{15} \mathrm{~N}$ depletion in components of a foodweb from an ephemeral boreal wetland compared to boreal lakes: putative evidence for microbial processes. Hydrobiologia 439:1-6

> Füreder L, Welter C, Jackson JK (2003) Dietary and stable isotope $\left(\delta^{13} \mathrm{C}, \delta^{15} \mathrm{~N}\right)$ analyses in alpine stream insects. Int Rev Hydrobiol 88:314-331

Gabler HM, Amundsen PA (2010) Feeding strategies, resource utilisation and potential mechanisms for competitive coexistence of Atlantic salmon and alpine bullhead in a sub-Arctic river. Aquat Ecol 44:325-336

> Gallagher CP, Dick TA (2011) Ecological characteristics of ninespine stickleback Pungitius pungitius from southern Baffin Island, Canada. Ecol Freshw Fish 20:646-655

> Grabowska J, Grabowski M, Kostecka A (2009) Diet and feeding habits of monkey goby (Neogobius fluviatilis) in a newly invaded area. Biol Invasions 11:2161-2170

Guo Z, Liu J, Lek S, Li Z and others (2012) Habitat segregation between two congeneric and introduced goby species. Fundam Appl Limnol 181:241-251

Guo Z, Cucherousset J, Lek S, Li Z, Zhu F, Tang J, Liu J (2013) Comparative study of the reproductive biology of two congeneric and introduced goby species: the implication for management strategies. Hydrobiologia 709:89-99

> Hammerschlag N, Heithaus MR, Serafy JE (2010) Influence of predation risk and food supply on nocturnal fish foraging distributions along a mangrove-seagrass ecotone. Mar Ecol Prog Ser 414:223-235

> Hyslop EJ (1980) Stomach content analysis - a review of methods and their application. J Fish Biol 17:411-429

Inger R, McDonald RA, Rogowski D, Jackson AL and others (2010) Do non-native invasive fish support elevated lamprey populations? J Appl Ecol 47:121-129

Kakareko T, Zbikowski J, Zytkowicz J (2005) Diet partitioning in summer of two syntopic neogobiids from two different habitats of the lower Vistula River, Poland. J Appl Ichthyol 21:292-295

Kaspersson R, Höjesjö J, Pedersen S (2010) Effects of density on foraging success and aggression in age-structured groups of brown trout. Anim Behav 79:709-715

Kim JW, Grant JWA (2007) Effects of patch shape and group size on the effectiveness of defence by juvenile convict cichlids. Anim Behav 73:275-280

Kleynhans EJ, Jolles AE, Bos MRE, Olff H (2011) Resource partitioning along multiple niche dimensions in differently sized African savanna grazers. Oikos 120:591-600

Kylafis G, Loreau M (2011) Niche construction in the light of niche theory. Ecol Lett 14:82-90

Levins R (1968) Evolution in changing environments. Princeton University Press, Princeton, NJ

Nakayama S, Fuiman LA (2010) Body size and vigilance

Editorial responsibility: L. Asbjørn Vøllestad, Oslo, Norway mediate asymmetric interference competition for food in fish larvae. Behav Ecol 21:708-713

Pianka ER (1973) The structure of lizard communities. Annu Rev Ecol Syst 4:53-74

> Pietrzak B, Grzesiuk M, Bednarska A (2010) Food quantity shapes life history and survival strategies in Daphnia magna (Cladocera). Hydrobiologia 643:51-54

- Polito MJ, Trivelpiece WZ, Karnovsky NJ, Ng E, Patterson WP, Emslie SD (2011) Integrating stomach content and stable isotope analyses to quantify the diets of pygoscelid penguins. PLoS ONE 6:e26642

> Post DM (2002) Using stable isotopes to estimate trophic position: models, methods, and assumptions. Ecology 83: 703-718

R Development Core Team (2012) R: a language and environment for statistical computing. R Foundation for Statistical Computing, Vienna. www.R-project.org

> Rodrigues FL, Vieira JP (2010) Feeding strategy of Menticirrhus americanus and Menticirrhus littoralis (Perciformes: Sciaenidae) juveniles in a sandy beach surf zone of Southern Brazil. Zoologia 27:873-880

Rusuwa B, Maruyama A, Yuma M (2009) Flexible trophic repertoire: food habits of Rhinogobius brunneus 'orange' (Pisces: Gobiidae) in the Ado River system, Japan. Malawi J Aquacult Fish 1:23-31

Shimose T, Yokawa K, Saito H (2010) Habitat and food partitioning of billfishes (Xiphioidei). J Fish Biol 76:2418-2433

Specziár A, Rezsu ET (2009) Feeding guilds and food resource partitioning in a lake fish assemblage: an ontogenetic approach. J Fish Biol 75:247-267

- Vizzini S, Sarà G, Michener RH, Mazzola A (2002) The role and contribution of the seagrass Posidonia oceanica (L.) Delile organic matter for secondary consumers as revealed by carbon and nitrogen stable isotope analysis. Acta Oecol 23:277-285

- Wasserman RJ (2012) Feeding ecology of the early life-history stages of two dominant gobiid species in the headwaters of a warm-temperate estuary. Estuar Coast Shelf Sci 109:11-19

Xie S, Cui Y, Zhang T, Li Z (2000) Seasonal patterns in feeding ecology of three small fishes in the Biandantang Lake, China. J Fish Biol 57:867-880

> Xie S, Li Z, Cui Y, Murphy BR (2005) Distribution, feeding and body condition of four small fish species in the nearshore and central areas of Liangzi Lake, China. Environ Biol Fishes 74:379-387

Xie Y, Li Z, Gregg WP, Li D (2001) Invasive species in China - an overview. Biodivers Conserv 10:1317-1341

Yin XW, Liu PF, Zhu SS, Chen XX (2010) Food selectivity of the herbivore Daphnia magna (Cladocera) and its impact on competition outcome between two freshwater green algae. Hydrobiologia 655:15-23

Yuan G, Ru H, Liu X (2010) Fish diversity and fishery resources in lakes of Yunnan Plateau during 2007-2008. J Lake Sci 22:837-841 (in Chinese with English abstract)

Zhang T (2005) Life-history strategies, trophic patterns and community structure in the fishes of Lake Biandantang. $\mathrm{PhD}$ dissertation, Chinese Academy of Sciences, Wuhan (in Chinese with English abstract)

Submitted: March 6, 2013; Accepted: July 30, 2013

Proofs received from author(s): November 28, 2013 